\title{
Incidence of Maize Ear Rot and Stem Borer Participatory Rural Appraisal Efficacy Relationship by Farmers in Western Kenya
}

\author{
Fredrick Wotia ${ }^{1,}$, Elizabeth Omukunda ${ }^{2}$ \\ ${ }^{1}$ Department of Agriculture and Land Use Management, School of Agriculture, Veterinary Sciences and Technology (SAVET), Masinde \\ Muliro University of Science and Technology (MMUST), Kakamega, Kenya \\ ${ }^{2}$ Department of Biological Sciences, Masinde Muliro University of Science and Technology (MMUST), Kakamega, Kenya
}

Email address:

fredwotia@gmail.com (F. Wotia)

${ }^{*}$ Corresponding author

\section{To cite this article:}

Fredrick Wotia, Elizabeth Omukunda. Incidence of Maize Ear Rot and Stem Borer Participatory Rural Appraisal efficacy Relationship by Farmers in Western Kenya. Plant. Vol. 9, No. 1, 2021, pp. 10-15. doi: 10.11648/j.plant.20210901.12

Received: December 30, 2020, Accepted: January 9, 2021, Published: January 22, 2021

\begin{abstract}
Maize has become Africa's second most important food crop after cassava. Maize is Kenya's staple food and is grown by about $90 \%$ of rural households. Among the pests and disease, stem borers are considered to be the most serious insect pests and ear rot the most important disease. A participatory rural appraisal (PRA) was carried out in Malakisi and Sirisia Divisions of Bungoma County, Western Kenya (N00 ${ }^{\circ} 68.824$ - N00 78.641 and E34 38.076 -E34 $4^{\circ} 55.604$ ). The PRA involved focused group discussions and 100 questionnaires were used in each Division to gather information from maize farmers. The focused groups consisted of the males and females who had engaged in maize production for at least 5 years. The two Divisions were perceived to have different levels of ear rot causing fungi because of different agro-ecological zones. This determined the farmers' knowledge on the relationship between maize ear rot and stem borer damage, yield losses and farmer's livelihoods. Farmers put $54 \%$ of their farms under maize production with mean yields of $9.8 \mathrm{bags} /$ acre and $10.9 \mathrm{bags} / \mathrm{acre}$ for Malakisi and Sirisia Divisions respectively. Most farmers planted maize early $78 \%$ and $83 \%$ for Malakisi and Sirisia. The use of certified seeds especially hybrids was high in both Divisions with Malakisi $74 \%$ while Sirisia had $84 \%$. Only $63 \%$ and $66 \%$ of the population for Malakisi and Sirisia respectively were food secure. The yields per unit area is far less than the potential due low levels of inorganic fertilizer use and unexploited organic manure utilization. But the government intervention/subsidy through National accelerated agricultural input and access programme (NAAIAP) programme in both Divisions realized significant increase in the yields of 20-30 bags /acre). All farmers affirmed knowing both maize stem borers and ear rot. The occurrence of stem borers was $16 \%$ in long rain season while $84 \%$ in short rains season. There were No stem borer tolerant varieties with farmers, local stockists and traders. Farmers in Malakisi $46 \%$ and Sirisia $37 \%$ recognized the relationship as a pathway between stem borer damage and ear rot incidence. Some farmers and traders admix their maize grains with Malakisi $25 \%$ and Sirisia $13 \%$. Rotten ears are used as livestock, poultry feeds, local brews and human food during hunger months. Coupled with the high number of traditional stores which are grass thatched and dilapidated, this predisposes the populace to mycotoxins associated with ear rot posing a health risk.
\end{abstract}

Keywords: Farmers, Incidence, Maize Ear Rot. Participatory Rural Appraisal, Stem Borer

\section{Introduction}

A major challenge facing developing countries is access to an adequate, safe and nutritious food supply. Maize is the third ranking cereal crop in the world after wheat and rice, accounting for about $20 \%$ of the global area under cereals [7,
8]. Maize is the dominant food staple in Eastern and Southern Africa, accounting for $40 \%$ of the calories consumed, mainly the poor, most of whom are women and children. Among the three major cereals, maize has the highest grain yield per unit area, with highest direct human consumption and contributes to huge financial value in global 
trade. Maize is grown in different agro-ecological zones ranging from lowland to highland tropics. Maize has become Africa's second most important food crop, after cassava. Maize is Kenya's staple food. It is a priority crop for small scale farmers in view of food security concern and is grown by about $90 \%$ of rural households with area under cultivation estimated at 1.6-1.88 million hectares [3-7, 14, 15]. Maize yields are low due to biotic and abiotic stresses such as drought, low soil fertility, pests and diseases. The greatest threat to maize production in Kenya is the pesky insect that attacks maize stalks and maize ear rot. Of the various insect pests attacking cereal crops in Africa, lepidopteron stalk borers are by far the most injurious $[1,6,13]$.

Maize ear rot is widespread and occurs worldwide where maize is grown [11, 23]. Maize ear rot is an important disease in Kenya and is caused by fungal complexes that belong to two main genera, Fusarium and Sternocarpella. Despite causing yield losses the ear rot fungi also contaminate infected grains with mycotoxins which pose a health risk to humans and animals consuming foods prepared from contaminated grain. Stalk borers crop yield losses are estimated to vary from 10 to $88 \%$, depending on the intensity of infestation $[1,10,12,21,25]$. Damage by stalk borers to the cob is known to enhance infection by the fungus [2]. In South Africa, Busseola. fusca increases the incidences of maize ears infected with $F$. moniliforme but not with Stenocarpella maydis [9] The means of entry for the damage was reported to be caused by the Asian maize borer (Ostrinia furnacalis) [26]. The aim of the study was to establish the farmer's knowledge on the relationship between the stem borer damage and ear rot incidence in Western Kenya.

\section{Materials and Methods}

\subsection{The Study Area}

The study was carried out in Bungoma West District of Bungoma County in Western Kenya in October to December 2010. The Geographical position system coordinates are $\mathrm{N} 00^{\circ} 68.824-\mathrm{N} 00^{\circ} 78.641$ and E34 ${ }^{\circ} 38.076-\mathrm{E} 34^{\circ} 55.604$. The study covered the two greater Divisions namely Malakisi and Sirisia of Bungoma West District. Table 1 shows the selected study sites and the number of farmers who were interviewed.

Table 1. Bungoma West District number of farmers interviewed.

\begin{tabular}{llllll}
\hline Sub-County & Division & Location & Male & Female & Total \\
\hline & & Malakisi & 20 & 14 & 34 \\
& \multirow{2}{*}{ MALAKISI } & Namubila & 12 & 9 & 21 \\
& & Lwandanyi & 15 & 11 & 26 \\
BUNGOMA & & Chepkuyi & 11 & 8 & 19 \\
WEST & & Sirisia & 23 & 12 & 35 \\
& \multirow{2}{*}{ SIRISIA } & Namwela & 13 & 9 & 22 \\
& & Bisunu & 9 & 5 & 14 \\
& & Toloso & 19 & 10 & 29 \\
& & Total & 122 & 78 & 200 \\
\hline
\end{tabular}

\subsection{Sampling Procedures}

Multi-stage sampling techniques were applied to select the study sites that represent diverse ecological and socioeconomic environment and varying maize production systems in the district. Malakisi is Agro ecological Lower midland three (AEZ LM 2-3 ) while Sirisia is Upper midland (AEZ UM). A hundred (100) farmers were randomly selected from four locations of the two divisions. A total of 200 of farmers were interviewed. The farmers were selected along a road across each location by picking farmers next to the road on both sides in a zig zag way and had practiced maize farming for at least 5 years.

\subsection{Data Collection and Analysis}

Primary and secondary data sources were utilized. The primary data were generated through interview of male and female farmers using Participatory Rural Appraisal (PRA) approaches. A checklist was developed. Data were collected from 200 interviewees composed of 123 male and 77 female farmers from the two divisions of Bungoma West (Table 1). Two focused group discussions were carried out thus one per Division. Secondary data were obtained from the Kenya Government establishments in the district. The research team comprised of the principal investigator, and Ministry of Agriculture staff under guidance of frontline agricultural staff. A Checklist was developed for administration for data collection. The staffs were taken through checklist to ascertain its adminisibility. The objectives of the project and communication procedures established to ensure that farmers and investigator/enumerators were at the same wavelength. The principal investigator also carried out one focused group discussion per Division. The farmers were asked to list maize varieties they grow, yields, proportions of their farms under maize, food security levels, knowledge on stalk borer, ear rot, their control, proportion loss due to ear rot, uses of rotten maize, use of certified seeds, fertilizers application, maize grading by farmers and seasons predominant with stem borers and ear rot. They were also asked to list the criteria they used in maize grading and constraints to maize production. The collected data were analyzed using the SPSS Package.

\section{Results}

\subsection{Participatory Appraisal Approach and Focused Group Discussions}

From the participatory appraisal approach 100 questionnaires were administered in each Division. The participation by gender was Malakisi Division 58 males and 42 females while Sirisia Division was 64 males and 36 females. One focussed group discussion was carried out in each Division.

\subsection{Maize Production and Food Security in Malakisi and Sirisia}

The results showed that the average farm size is 1.66 ha and 1.51 ha for Malakisi and Sirisia divisions respectively. The proportions of farms under maize production are $58 \%$ 
and $50 \%$ for Malakisi and Sirisia divisions respectively giving an average of $54 \%$ of total land area under maize production. The average yields per acre were 9.8 bags and
10.9 bags (of 90kg) for Malakisi and Sirisia divisions respectively (Table 2).

Table 2. Maize yield levels in Malakisi and Sirisia divisions.

\begin{tabular}{lllll}
\hline \multirow{2}{*}{ Yields/Acre in bags (90kg) } & Malakisi & \multicolumn{3}{c}{ Sirisia } \\
\cline { 2 - 5 } & Number of farmers & $\mathbf{\%}$ & Number of farmers & \% \\
\hline $0-5$ & 11 & 16.7 & 12 & 23 \\
$6-10$ & 40 & 58.3 & 21 & 38.5 \\
$11-20$ & 11 & 16.7 & 17 & 30.7 \\
$21+$ & 6 & 8.3 & 4 & 7.8 \\
\hline
\end{tabular}

\subsection{Maize Stem Borer Occurrence in Malakisi and Sirisia}

All farmers in both divisions perceived to know stem borers and their effects in maize and their host plants. The stem borers are known by various names by the three predominant ethnic groups in the two divisions namely
Luhyia (Bukusu), Sabaoti and Teso. The farmers confirmed the presence of stem borers on their farms in both seasons for Malakisi and Sirisia. The occurrence of stem borers is proportionately high during the second season with an average of $84 \%$ while the first season with $16 \%$ (Table 3).

Table 3. Maize stem borer occurrence by seasons in Malakisi and Sirisia.

\begin{tabular}{llllll}
\hline \multirow{2}{*}{ Seasons } & Malakisi & & Sirisia & \multicolumn{2}{l}{ Malakisi and Sirisia combined } \\
\cline { 2 - 6 } & Number of farmers & $\mathbf{\%}$ & Number of farmers & \% & (\%) \\
\hline 1- Long rain & 13 & 19 & 7 & 13.75 & 16.4 \\
2- Short rain & 55 & 81 & 47 & 86.25 & 83.6 \\
\hline
\end{tabular}

The proportion of farmers who controlled stem borers in Malakisi is $53.5 \%$ as compared to Sirisia with $28.6 \%$. Most farmers controlled stem borers by the following methods, traditional $(62.7 \%)$, cultural $(19.7 \%)$ and chemical $(17.6 \%)$
(Table 4). There are no stem borer tolerant maize varieties with farmers in both divisions. The traditional methods included the use of ash, ash + hot pepper admix. The chemicals used are Bulldock and Dipterex granules.

Table 4. Maize stem borer control methods by famers in Malakisi and Sirisia.

\begin{tabular}{|c|c|c|c|c|c|}
\hline \multirow{2}{*}{ Control method } & \multicolumn{2}{|l|}{ Malakisi } & \multicolumn{2}{|l|}{ Sirisia } & \multirow{2}{*}{ Malakisi and Sirisia combined \% } \\
\hline & No. of farmers & $\%$ & No. of farmers & $\%$ & \\
\hline Chemicals & 15 & 22.7 & 7 & 12.5 & 17.6 \\
\hline Traditional methods & 37 & 54.6 & 38 & 70.8 & 62.7 \\
\hline Cultural & 15 & 22.7 & 9 & 16.7 & 19.7 \\
\hline Tolerant maize varieties & 0 & 0 & 0 & 0 & 0 \\
\hline
\end{tabular}

\subsection{Maize Ear rot Occurrence in Malakisi and Sirisia}

All the farmers interviewed knew ear rot and confirmed to have observed them on their farms during the seasons. The ear rot is known by various names by the three predominant ethnic groups in the two divisions. The ethnic groups are Luhya (Bukusu), Sabaoti and Teso. The local names were 'Kamabolo', 'Mbokok' and 'Ekurididi ekabosan'. The proportion of farmers who perceived that stem borers predisposed maize to ear rot is $46 \%$ and $37 \%$ for Malakisi and Sirisia divisions respectively. On overall for both divisions $41.5 \%$ of farmers perceived the relationship. Most ear rot occurred in the long rains season in both divisions with an average proportion of $87 \%$ than in the short rains with average proportion of $13 \%$. This was due to high rainfall and delayed harvesting of mature maize (Table 5).

Table 5. Occurrence of maize ear rot by season in Malakisi and Sirisia.

\begin{tabular}{|c|c|c|c|c|c|}
\hline & \multicolumn{2}{|c|}{ Malakisi division } & \multicolumn{2}{|l|}{ Sirisia division } & \multirow{2}{*}{$\begin{array}{l}\text { Malakisi and Sirisia combined } \\
\%\end{array}$} \\
\hline & No. of farmers & $\%$ & No. of farmers & $\%$ & \\
\hline Long rains season & 57 & 84 & 49 & 90 & 87 \\
\hline Short rain season & 11 & 16 & 5 & 10 & 13 \\
\hline
\end{tabular}

The proportion of farmers who controlled ear rot is $17 \%$ and $32 \%$ for Malakisi and Sirisia respectively i.e. an average of $24.5 \%$ (Table 6 ). Those who controlled used methods such as early planting, timely harvesting and harvested maize at the correct moisture content at harvested and stored in well ventilated structures. 
Table 6. Proportion of farmers controlled maize ear rot in Malakisi and Sirisia.

\begin{tabular}{llllll}
\hline \multirow{2}{*}{ Measures } & Malakisi Division & \multicolumn{3}{c}{ Sirisia Division } & Malakisi and Sirisia combined (\%) \\
\cline { 2 - 5 } & No. of farmers & $\mathbf{\%}$ & No. of farmers & $\mathbf{\%}$ & \\
\hline Control & 12 & 17 & 17 & 32 & 24.5 \\
No control & 56 & 83 & 37 & 68 & 75.5 \\
\hline
\end{tabular}

Table 7. Ranking of maize varieties susceptible to maize ear rot by farmers in Malakisi and Sirisia.

\begin{tabular}{|c|c|c|c|c|c|}
\hline \multirow{2}{*}{$\begin{array}{l}\text { Malakisi Division } \\
\text { Maize variety } \\
\end{array}$} & \multicolumn{5}{|c|}{ Sirisia Division } \\
\hline & No. of farmers & Rank & Maize variety & No. of farmers & Rank \\
\hline PH4 & 15 & 1 & H624 & 16 & 1 \\
\hline $\mathrm{H} 624$ & 13 & 2 & DH04 & 10 & 2 \\
\hline WH505 & 11 & 3 & H625 & 7 & 3 \\
\hline H625 & 7 & 4 & H513 & 6 & 4 \\
\hline H513 & 6 & 6 & PAN67 & 5 & 5 \\
\hline H614 & 5 & 7 & H6210 & 4 & 6 \\
\hline $\mathrm{H} 628$ & 5 & 7 & No. 8 local & 4 & 6 \\
\hline DH04 & 4 & 8 & H614 & 3 & 7 \\
\hline NO. 8-Local & 2 & 9 & H520 & 1 & 8 \\
\hline
\end{tabular}

The maize varieties with least number of rotten ears are H520, H614, and local No. 8, H628 and those with average number of rotten ears are PAN67, H625, H513, and WH505. Those with high number of rotten ears are H624, PH04 and DH04. Though some farmers had not planted correct varieties for the ecological requirements (Table 7).

On post-harvest management the proportion of farmers who owned crib stores is only $10 \%$ and $15 \%$ for Malakisi and Sirisia respectively. Majority of the farmers owned traditional granaries where Malakisi and Sirisia had $70 \%$ and $60 \%$ respectively. Most of these granaries were poorly maintained and had dilapidated roof tops. The roofs were grass thatched. The other proportions of farmers kept their maize in their living rooms as shelled and or stored in sacks.

\subsection{Maize Grading and Utilization by Farmers in Malakisi and Sirisia}

The proportions of farmers that graded their maize before storing are $73 \%$ and $80 \%$ for Malakisi and Sirisia respectively. The criteria they used are absence of rotten ears, size of the ears, and colour of the grains. The farmers that discarded the whole maize ear though partially rotten are $33.3 \%$ and $14 \%$ for Malakisi and Sirisia respectively. Farmers that disposed the partially rotten part only and retained the 'clean' parts are $41.7 \%$ and $73 \%$ for Malakisi and Sirisia, while those who mixed are $25 \%$ and $13 \%$ for Malakisi and Sirisia respectively (Table 8).

Table 8. Proportion of farmers who grade and sort harvested maize in Malakisi and Sirisia.

\begin{tabular}{llll}
\hline Sub-County & \% of farmers who dispose whole rotten ear & \% of farmers who dispose the rotten part only & \% of farmer who mix \\
\hline Malakisi & 33.3 & 41.7 \\
Sirisia & 14.0 & 73.0 & 25.0 \\
\hline
\end{tabular}

The results revealed that farmers acknowledged the effects of using rotten maize such as stomach upsets but farmers in both two Divisions still used rotten maize for various purposes such as livestock feed, poultry feed and local brews such as Busaa, 'Kangara' and Changaa'.

\section{Discussion}

The results from the participatory rural appraisal showed that farmers put approximately $54 \%$ of their farms under maize production. This is less than $95 \%$ as reported in Zambia [17]. Most farmers plant early thus within one month upon onset of rains and this was $79 \%$ and $83 \%$ for Malakisi and Sirisia respectively. Maize growth is primarily determined by the soil temperatures and the maize crops can utilize the nitrogen effect within this period. The adoption rate for certified maize seeds was high at $74 \%$ and $84 \%$ for Malakisi and Sirisia Divisions respectively. This is comparable to $70.7 \%$ [17] but not in agreement to $20 \%$ [20]
The presence of various extension agents particularly the seed companies such as Kenya Seed Company, Pannar seeds, Western Seed Company, and the ministry of agriculture have immensely contributed to the uptake. This has been through Barazas, demonstrations and field days. Although there were some farmers who did not use certified seed in Malakisi (26\%), and Sirisia (16\%). This is low in contrast with $77-97 \%[20,22]$. Most of this category of farmers was the resource poor. They planted local seed called number Nane, previous' season seed or mixed the certified with either the local or previous season seed. Though most farmers used certified maize seed deemed to be high yielding, the mean yields of 9.8 and 10.9 bags /acre for Malakisi and Sirisia Divisions respectively. The low yields were attributed to low use of fertilizers, stem borer damage, ear rot, soil erosion and poor storage of harvested maize. The yields were low because only an average number of farmers use the full recommended fertilizer in both Malakisi and Sirisia. The high prices of inorganic 
fertilizer were prohibitive and out of reach of most small scale resource poor farmers. The realization of the potential yields of hybrid maize is determined by several agronomic practices where fertilizer use is fundamental. The low yields could not guarantee food security throughout the year for the households. Malakisi had 63\% while Sirisia $66 \%$ of farmers who were food secure. The situation is aggravated when majority of farmers who sale their maize cheaply at harvest to meet other domestic needs. The interventions by the government and development partners through programmes such National accelerated agricultural input and access programme (NAAIAP) and the subsidized fertilizer through the National cereals and produce board (NCPB) tried to alleviate the problem. The NAAIAP had benefited resource poor farmers for two years where each farmer received inputs $(50 \mathrm{~kg}$ basal fertilizer, $10 \mathrm{~kg}$ of certified maize seed and $50 \mathrm{~kg}$ of topdressing fertilizer) for one acre of maize. The yields from these farmers increased from an average of 3-6 bags per acre to 20-30bags per acre. The farmers have been sensitized about the subsidized fertilizers. There is still low use of organic manures by farmers to supplement.

All the farmers affirmed to know stem borers courtesy of agricultural extension agents in the areas through demonstrations and field days. This was higher than that of $50 \%$ in Kapuchorwa in Uganda $[16,21]$ and comparable to $82.1 \%$ in Cameroon [19]. Most of the stem borers incidence and damage occur during the short rain season (84\%) than in the long rain season of (16\%). The built up of the stem borer larvae and rubble left in the field after the first harvest acts as a reservoir. There were also cases of occurrence in late planted maize. More farmers in Malakisi (53.8\%) than in Sirisia (28.5\%) control stem borers. The Malakisi scenario is in agreement with $25 \%$ in KwaZulu Natal -South Africa [22]. Majority of the farmers $(62.7 \%)$ use traditional methods and only $(17.6 \%)$ use chemicals. But pesticide control was most common in Uganda and Cameroon [18, 19]. The traditional methods include ash, ash + hot pepper admix presumably cheaper, environmentally friendly as compared to conventional pesticides. The packaging units are also not friendly to small scale farmers who may require just small amounts to use. There were no stem borer tolerant maize varieties with farmers or local stockists although research has been done [24]. KALRO Kakamega had released KM0404, KM0406 hybrids and KM0403-OPV which is open pollinated in 2007.

All the farmers were aware of maize ear rot confirming earlier findings [23]. But only $46 \%$ and $37 \%$ of farmers in Malakisi and Sirisia established that stem borers predisposes maize to ear rot. They illustrated how stem borer damage serves as a pathway for fungi that cause maize ear rot. Other reasons advanced were bird damage, heavy rainfall, lodging, fungi infestation, and poor storage. Most of the ear rot occurs (87\%) during the first season (long rains) presumably aggravated by heavy rains and in cases of delayed harvesting of mature maize. Farmers who control ear rot were Malakisi $17 \%$ and Sirisia $32 \%$. They control through early planting, timely harvesting and ensuring proper storage. Most farmers in both Divisions harvest their maize timely. But farmers harvesting at just physiological point like the case for Malakisi Division should be advised on the need for proper drying of the harvested maize. The high moisture content my predispose maize to fungal growth. The farmers carry out this to pave way for relay cropping with crops such as sweet potatoes, beans or engage in horticultural crops such tomatoes, onions. Through ranking Malakisi and Sirisia the maize varieties with low rotten ears were H520, H516, and NDUMA, WH403 those with medium rotten ears were local seed, PAN67, H6210, H614, and WH505. Those with high rotten ears were H624, PH04, DH04, H625, and H513. Some farmers had not planted correct varieties per the agro-ecological zone or recommendation. At harvesting farmers still do partial sorting and grading and some admix the rotten maize. Farmers in Malakisi $25.0 \%$ admix while Sirisia $13.0 \%$. Though farmers acknowledge the effects of using rotten maize such as stomach ache, poor digestion and bloat but farmers still use the rotten maize as livestock, poultry feeds, preparation of local brews ('Busaa', 'Kangara' and 'Changaa') as confirmed by earlier findings $[1,16]$. Some resource poor farmers resort to 'rotten' maize for food during hunger months. Unscrupulous traders admix clean and rotten before selling. Through the food chain the farmers risk the effects of mycotoxins associated with ear rot fungi. The number of farmers with crib stores was $10 \%$ and $15 \%$ in Malakisi and Sirisia Divisions respectively. Earlier findings in Trans Nzoia had 42\% [26]. The size and the type of store are largely dictated by the amount of harvestable maize yields. Malakisi had $70 \%$ and Sirisia $60 \%$ traditional granaries while Trans Nzioa had 17\% [26]. Most of them were grass thatched, dilapidated that predisposed maize to ear rot.

\section{Conclusion}

The adoption of certified maize seed stands is high $79 \%$ but the yields still remarkably low due to inadequate use of inputs and other agronomic practices. All farmers affirmed the occurrence of stem borers and maize ear rots on their farms. Stem borer damage was highest during the short rain season while maize ear rot incidence was high during the long rain season. A proportion of $41.5 \%$ of farmers perceived the relationship that stem borer damage predisposes maize to ear rot. Most of the farmers use traditional methods in the management of stem borers. There are no stem borer tolerant maize varieties with farmers. Farmers still use rotten maize as human food and livestock feed oblivion of the risks associated with mycotoxins.

\section{Recommendation}

I. More sensitization to farmers is expected to curb the risk of mycotoxins arising from maize ear rot.

II. The researchers need to hasten the breeding, the release and promotion of stem borer resistant maize varieties among the farmers. 


\section{Acknowledgements}

We the authors thank Teresa Waswa, Martin Walela, Wycliffee Wekesa, Felix Wamukota, Chrisostim Wanyonyi from Ministry of Agriculture- Bungoma County for their help with the field work.

The farmers from Malakisi and Sirisia Divisions for their collaboration have provided necessary information for this study.

\section{References}

[1] Ajanga, S. M. (2000). Maize Ear Rots and Associated Mycotoxins in Western Kenya. Ph. D. Thesis, University of Greenwich, UK.

[2] Drepper, W. J., Renfro, B. L. (1990b). Incidence of maize ear rot caused by Fusarium moniliforme and Stenocarpella maydis in South African Journal of Plant and Soil. 9: 177-179.

[3] Economic Review of Agriculture. (2007). Central Planning and Monitoring Unit, Ministry of Agriculture, Republic of Kenya. pp. 17.

[4] Economic Review of Agriculture (2009). Central Planning and Monitoring Unit, Ministry of Agriculture, Republic of Kenya. pp. $23-25$.

[5] Economic Review of Agriculture (2010). Central Planning and Monitoring Unit, Ministry of Agriculture, Republic of Kenya. pp. $25-26$.

[6] Export Processing Zone. (2005). Grain production in Kenya, Nairobi, EPZ. pp. 6.

[7] FAO (2005). FAOSTAT Data, Faostat, FAO. Org. $2^{\text {nd }}$ February 2006.

[8] FAO

(2010).

FAOSTAT http://faostat.fao.org/site/567/default/.aspx

[9] Flett, B. C. and van Rensburg, J. B. J. (1992). Effect of Busseola fusca on the incidence of maize ear rot caused by Fusarium moniliforme and Stenocarpella maydis. South African Journal of Plant Soil. 9: 177-179.

[10] Kalule, T., Ogenga-Latigo, M. W. and Okoth, V. A. O. (1997). Seasonal fluctuations and damage of lepidopteran stem borers on maize in a major agro eco zone of Uganda. In African Crop Sci. J. 5: 385-393.

[11] Kedera, J. C., Ochor, E. T., Ochieng, W. A. J. and Kamindi, E. R. (1994). Incidence of maize ear rot in Western Kenya, in Int. J. Pest Man. 40: 117-120.

[12] Kfir, R., Overholt, W. A., Khan, Z. R., Polaszek, A. (2002). Biology and management of economically important lepidopteran cereal stem borers in Africa. Annu. Rev. Entomol. 47: 701-731.

[13] KMDP. (2007). Kenya Maize Handbook, ACDI/VOCAKenya Training Manual No. 27.
[14] MoA (2009). Annual report, Crops Development Division. Nairobi.

[15] MSPND. (2009a). Bungoma west, District Development Plan 2008-2012. pp. 13-16.

[16] MSPND. (2009b). Food Survey Report-Kenya. pp. 12-14.

[17] Mukanga, M., Derera, J., Tongoona, P., \& Laing, M. (2011). Farmers' perceptions and management of maize ear rots and their implications for breeding for resistance.

[18] Mutitu, E. W., Narla, R., Oduor, H and Gathumbi, K. J. (2003). Causes of ear rot of maize with mycotoxin implications in Eastern and Central Kenya, in Proceedings of Book of Abstracts for the 6th Biennial Conference of the African Crop Science Society, Oct. 12-17, Nairobi, Kenya. pp. $71-71$

[19] Oben, Esther \& Ntonifor, Nelson \& Kekeunou, Sévilor \& Abbeytakor, Martin. (2015). Farmers knowledge and perception on maize stem borers and their indigenous control methods in south western region of Cameroon. Journal of Ethnobiology and Ethnomedicine. 11. 10.1186/s13002-0150061-z.

[20] Odendo, Martins, De Groote, Hugo, Odongo, Omari and Oucho Patrick (2002). Participatory Rural Appraisal of Farmers' Criteria for Selection of Maize Varieties and Constraints to Maize Production in Moist-Midaltitude Zone of Western Kenya. A case study of Butere-Mumias, Busia and Homa Bay Districts

[21] Odendo, M., Wachira, S., Wanyama, J. (2003). Economic assessment of maize yield loss due to stem borer in major maize agro-ecological zones of Kenya, African crop science conference proceedings $6: 683-687$.

[22] Sibiya Julia, Pangirayi Tongoona1, John Derera1 and Itai Makanda (2013). Smallholder farmers' perceptions of maize diseases, pests, and other production constraints, their implications for maize breeding and evaluation of local maize cultivars in KwaZulu-Natal, South Africa. African Journal of Agricultural Research, Vol. 8 (17), pp. 1790-1798. DOI: 10.5897/AJAR 12.1906

[23] Shurtleff, M. C (1980). Compedium of corn diseases. American phytopathological society, 2nd eds. St Paul, MN, USA.

[24] Tefera, T., Mugo, S., \& Beyene, Y. (2015). Developing and deploying insect resistant maize varieties to reduce pre-and post-harvest food losses in Africa. Food Security, 8, 211-220. DOI: $10.1007 / \mathrm{s} 12571-015-0537-7$

[25] Warui, C. M. and Kuria, J. N. (1983). Population incidence and the control of maize stem borers, Chilo partellus Swinhoe, C. orichalcociliellus Strand and Sesamia calamistis Hampson in Coast Kenya in Kenya. Insect Sci. Applic. 4: 11-18.

[26] Xia, Z. H., Pan, H. K., Zhang, L. X., Liu, C. Y. (1995). The relationship between maize ear rot caused by Fusarium moniliforme and maize ear-feeding rate caused by Asian borer (Ostrinia furnacalis), Acta Agriculturae Boreali Sinica. 10: 88-91. 